\title{
Measles virus and subacute neurological disease: an unusual presentation of measles inclusion body encephalitis
}

\author{
DW CHADWICK, S MARTIN, PH BUXTON, AH TOMLINSON* \\ From the Mersey Regional Department of Medical and Surgical Neurology, Walton Hospital, Liverpool and \\ the Department of Virology, ${ }^{*}$ Public Health Laboratory, John Radcliffe Hospital, Oxford, UK
}

SUMMARY A 20-year-old girl developed a subacute neurological illness characterised by seizures and epilepsia partialis continua, which resulted in her death within 10 weeks of her first symptom. Although she had a history of unusual reactions to viral infections, there was no evidence of any underlying disorder resulting in immunosuppression. Histopathology demonstrated the presence of dense infection with measles virus. The unusual clinical features of this cases suggest that measles virus may be responsible for a wide spectrum of neurological disease ranging from measles inclusion body encephalitis on the one hand to subacute sclerosing panencephalitis on the other.

Measles virus may cause both an acute postinfectious meningo-encephalitis, and persisting central nervous system infection resulting in the clinical syndrome of subacute sclerosing panencephalitis.' The role of altered immunity in subacute sclerosing panencephalitis has been much debated, but the strongest evidence now indicates that measles virus may persist in the central nervous system because in certain cells of the brain the " $\mathrm{M}$ " protein is not synthesised. ${ }^{2}$ Altered immunity may, however, modify the clinical consequences of measles infection, and it is well-recognised that immuno-suppressed patients may develop a rapidly progressive illness, characterised by focal seizures and coma following measles infection. ${ }^{3-5}$ Such cases are likely to increase our understanding of host-virus interaction in measles-induced neurological disease.

We now report a case in which there was a subacute progressive illness characterised by focal seizures, epilepsia partialis continua and decline in consciousness, leading to death within ten weeks. The patient had a history of unusual reactions to viral infection, but there was no history of a recent acute measles infection. Necropsy demonstrated the presence of eosinophilic inclusion bodies which fixed measles antibody.

Address for reprint requests: Dr DW Chadwick, Walton Hospital, Rice Lane, Liverpool, L9 1AE, UK.

Received 11 March 1982

Accepted 9 April 1982

\section{Case report}

A 20-year-old female university student, successfully studying modern languages, developed a repetitive, persisting jerking of the left calf muscles. This continued for three to four days before she developed some occasional twitching of the muscles on the right side of her face. A week after the first symptom she had a more extensive right sided focal motor seizure involving the arm, which culminated in a generalised tonic-clonic seizure precipitating her admission to hospital.

She recovered consciousness and was lucid, although jerking of the right facial muscles continued. Over the next day, during which she was noted to be pyrexial $\left(37.5^{\circ} \mathrm{C}\right)$, the rhythmic jerking of the right face spread to involve the right hand, and she began to exhibit confusion. In spite of anticonvulsant therapy she had further tonic-clonic seizures and her conscious level deteriorated. She showed no evidence of neck stiffness but mild pyrexia continued. Other than a tachycardia there were no other abnormal findings, and no exanthematous rash was noted. Two weeks into her illness she was unconscious with occasional spontaneous eye-opening and grimacing to painful stimuli. No spontaneous movements occurred on the left, and upper limb tendon reflexes were absent. Over the subsequent two weeks the continuous jerking affecting the right face and arm subsided but she developed similar continuous repetitive jerking affecting the left arm and face. For a period of a few days this jerking was present both on the right and the left but at differing rates on the two sides. Her condition deteriorated whilst on treatment with dexamethasone and anticonvulsant drugs, and she died ten weeks after the onset of her illness.

There was no history of preceding rash or upper 
respiratory tract infection, and the only prior medical history of note was that at the age of two she had developed a localised herpetic eruption in a thoracic distribution, and at the age of six had had a further episode of right ophthalmic herpes zoster. She had clinical rubeola between these dates.

On admission to hospital, haemoglobin was $12.9 \mathrm{~g} / \mathrm{dl}$, and peripheral white cell count $9.1 \times 10^{9} / 1$ with a normal differential count. ESR was $46 \mathrm{~mm} / \mathrm{hr}$ and plasma, urea and electrolytes and liver function tests were normal. Radiographs of skull and chest were normal. CSF examinations were performed on several occasions during her illness. CSF total protein varied between 0.2 and $0.4 \mathrm{~g} / \mathrm{l}$. CSF glucose was normal and, apart from two initial specimens

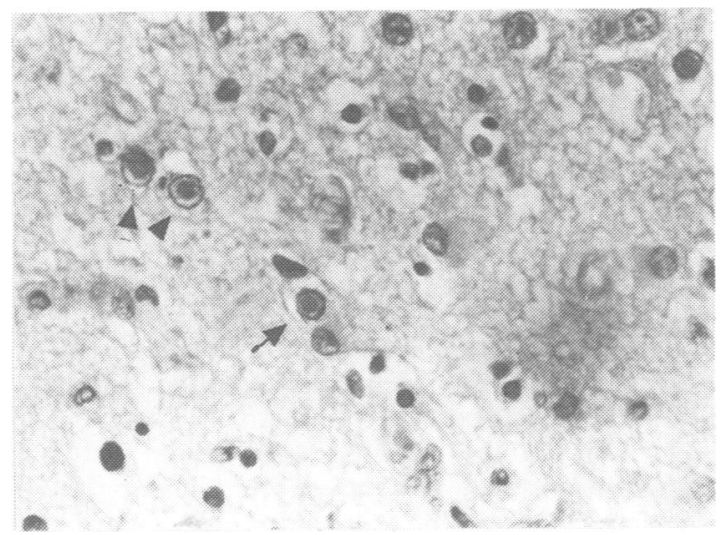

Fig 1 Intranuclear inclusions (arrows) Phloxine-tartrazine $\times 220$. in which there were lymphocytes $7 / \mathrm{cmm}$, there was no increased cellularity. CSF IgG was $0.036 \mathrm{~g} / \mathrm{l}$ (normal range 0-013-0-14) and CSF IgG/albumin ratio was not disturbed. Serum and CSF viral antibodies did not show any change in titres at 6, 13 and 27 days into the illness. In particular, measles, and herpes simplex virus antibodies were present in the serum at a titre of $1: 160$. Whilst herpes simplex antibodies were not detectable in CSF at any time, the measles antibody titre in CSF was $1: 4$ on day 13 of the illness, and 1:2 on day 27. EEGs were performed throughout the illness. These initially showed a generalised diffuse slow wave disturbance. However there was a progressive change with the development of high voltage periodic spike-slow wave complexes. CT scanning 10 days into the illness was entirely normal, but at six weeks a low density lesion in the right temporo-parietal region was evident,

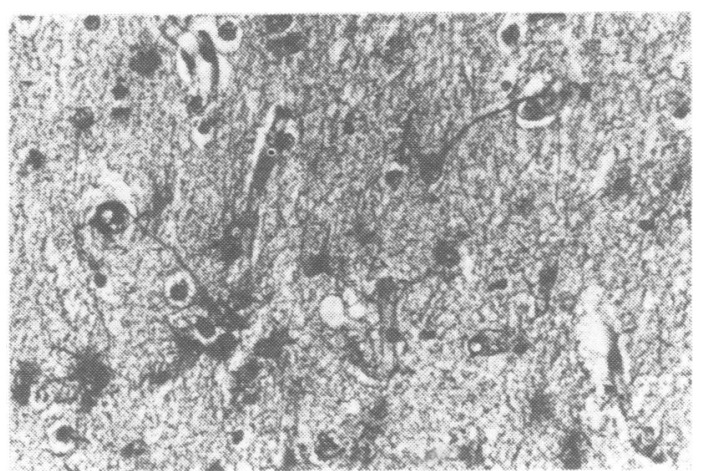

Fig 2 Dense fibrillary gliosis in right central grey matter. $P T A H \times 215$.

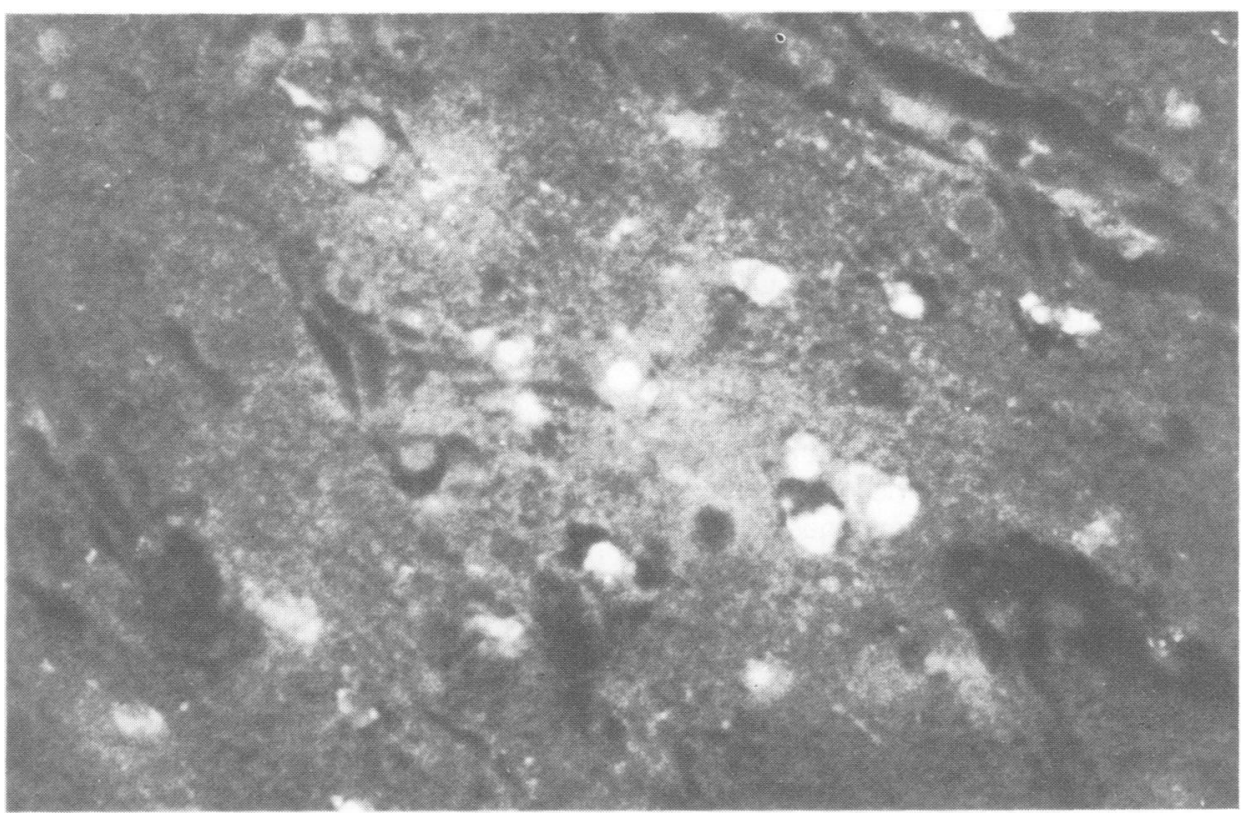

Fig 3 Measles virus antigen, stained with fuorescent antibody, in cells of the right central grey matter. 
which did not show contrast enhancement. Six weeks into the illness a right frontal cortical biopsy was performed. This showed gross loss and degeneration of cortical neurones with moderate glial infiltration. Blood vessels appeared normal and there was no evidence of perivascular cuffiing. A deeper needle biopsy showed a patchy loss of myelin and areas of spongiose change. Inclusion bodies were not identified.

At necropsy the brain showed flattening of the cortical sulci and congestion of cortical veins. Venous sinuses were patent and the arachnoid at the base of the brain slightly thickened. The spinal cord appeared normal as did other organs. Micropsy showed considerable neural destruction which was most severe in the right temporal cortex and the right central grey matter. Typical eosinophilic intranuclear inclusions were seen in both neurones and glia (fig 1). Cortical destruction was accompanied by considerable fibrillary glial increase (fig 2). Perivascular round cell cuffing was seen in a few areas and occasional macrophages were present. These appearances strongly suggested a viral aetiology to the patient's illness.

Immunofluorescent staining (carried out by AHT) failed to detect antigen to herpes simplex virus, but staining with rabbit anti-measles serum showed many infected neuronal and glial cells in the frontal and temporal lobes and central grey matter of both hemispheres (fig 3). Human serum from a case of subacute sclerosing panencephalitis gave the same staining pattern and controls using rabbit and human serum devoid of measles antibody were negative. The findings all suggested a heavy infection with measles virus despite the modest serum and CSF antibody titres. Further studies with potent anti-measles serum (kindly donated by Dr Margaret Haire) and PAP immuno-staining of the original surgical cortical biopsy sections demonstrated occasional infected neurons in this biopsy, and also in few anterior horn cell neurons at different levels in the spinal cord.

\section{Discussion}

This patient presented at the age of 20 years with a rapidly progressive illness characterised by focal epilepsy, epilepsia partialis continua and generalised seizures which resulted in death within ten weeks of the onset of the first symptom. The histopathology and labelled antibody studies showed the presence of a dense and widespread infection with measles virus. The clinical features of this patient's illness are similar to those previously described in a number of patients under the titles of "immunosuppressive measles encephalitis", 6 "subacute measles encephalitis", ' and "acute measles encephalitis of the delayed type". ${ }^{8}$ We prefer the term "measles inclusion-body encephalitis" as this satisfactorily differentiates this condition from post-infectious measles encephalitis.

This condition was first described by Lyon $^{3}$ in a patient with nephrosis. Agamonolis et al ${ }^{10}$ recently reviewed the literature and clinical features of some
24 cases. The clinical features were in every way similar to those of our patient. Focal seizures, and epilepsia partialis continua were prominent, and associated with a rapid decline into coma. Death within a period of weeks was the rule, although occasional prolonged survival has been recorded. A more recently reported case showed a similar sequence of events. ${ }^{11}$

However, the disorder is usually seen in children, and only two previous cases have been reported in patients over the age of twelve. ${ }^{10}$ The condition is strongly associated with disorders in which there is impaired immunity (most commonly acute lymphatic leukaemia but also other lymph-proliferative disorders, nephrosis, neuroblastoma, and renal transplantation). Many patients have also received chemotherapy.

Our patient would seem to be unusual in not suffering from any clearly recognisable underlying immune disorder. She did however have a history of two episodes of herpes zoster in early life. It may be that this patient had a specific immune deficiency in responding to viral infections capable of remaining dormant within the central nervous system. Whilst her immune system was not studied formally, the minimal antibody response to measles in CSF and serum would support this supposition. Only one patient has previously been reported in whom there was no preceding illness or therapy associated with immunosuppression. ${ }^{8}$

A further unusual feature of the present case is that unlike the majority of cases of measles inclusion body encephalitis there was no recent clinical rubeola. A similar absence of such a history has been reported in six patients..$^{510^{12-14}}$ It is notable that in both the older patients thus far reported there was a similar absence of recent rubeola infection $^{710}$ It thus appears that measles inclusion body encephalitis may well arise because of activation of a long-standing persistent measles infection, as well as the more common situation in which it develops within a period of months of rubeola infection.

This present case is similar to the case reported by Mandelbaum $\mathrm{et}^{\mathrm{al}} \mathrm{l}^{15}$ as subacute sclerosing panencephalitis in an otherwise normal 14 year-old-boy, and to that reported by Coulter $e^{2}$ al $^{16}$ as a case of subacute sclerosing panencephalitis after drug-induced immunosuppression. The latter patient, suffering from a neuroblastoma, had received radiotherapy and chemotherapy ten years previously. She developed an illness which over four months led to deteriorating intellectual performance with subsequent focal seizures, myoclonic jerks and epilepsia partialis continua. This patient showed high complement fixing titres to measles virus in both serum and CSF and typical EEG changes of subacute 
sclerosing panencephalitis. There was no clear-cut recent rubeola infection. There seems no reason to differentiate these cases from others described as immunosuppressive measles encephalitis or measles inclusion body encephalitis. It does however raise the question of the adequacy of definition of two differing clinical entities.

The criteria for diagnosis of subacute sclerosing panencephalitis are dependant on the characteristic clinical picture, electroencephalographic appearances, the presence of measles antibody titres in serum and cerebrospinal fluid and typical histopathological changes. ${ }^{17}$ Both measles inclusion body encephalitis and subacute sclerosing panencephalitis may share similar EEG appearances, and histopathological changes including immunocytological demonstration of intraneuronal measles antigen. Whilst in some cases high measles antibody titres in serum and CSF may not be found in measles inclusion body encephalitis some cases show titres as high as those to be expected in subacute sclerosing panencephalitis. ${ }^{10}$ It therefore seems that the major criteria for differentiating between these two conditions is the clinical picture.

In subacute sclerosing panencephalitis the classical presentation and progress of the condition has been well-defined, with subdivision into four clinical stages. ${ }^{18}$ In stage $I$ there is subtle intellectual and behavioural change, sometimes associated with convulsions, tremors, and chorioretinitis. In stage II ataxia develops along with generalised myoclonic jerks associated with periodic EEG complexes. Coma and decerebration develop in stage III. In stage IV myoclonus and spasticity diminish and death ensues. The characteristic focal seizures, epilepsia partialis continua, and generalised convulsion of measles inclusion body encephalitis are rarely seen in subacute sclerosing panencephalitis. The presence of epilepsia partialis continua, an unusual form of focal epilepsy, may be particularly helpful in making the diagnosis of measles inclusion body encephalitis. Measles inclusion body encephalitis was not included as a cause of epilepsia partialis continua in a recent comprehensive review of the subject. ${ }^{19}$ The frequency with which it occurs in measles inclusion body encephalitis needs to be emphasised.

Nevertheless, there are grounds for suggesting that the two entities form part of a spectrum of neurological disorder caused by measles virus. As well as similarities in the histopathology, and EEG changes, there may be a continuous clinical spectrum. Up to $10 \%$ of patients with subacute sclerosing panencephalitis have a rapidly progressive illness. ${ }^{20}$ Whilst the clinical features of these acute cases are poorly described, some may be atypical in the clinical course of the illness, ${ }^{21}$ and seizures may be a prominent presenting feature. ${ }^{22}$ Conversely some patients with measles inclusion body encephalitis may survive for prolonged periods. ${ }^{1423}$ Whilst subacute sclerosing panencephalitis usually has a much longer incubation period than measles inclusion body encephalitis, in our patient and in others, a typical inclusion body encephalitis syndrome may develop many years after a clinical measles infection. The growth of measles virus in neurons and glial cells is similar in the two conditions in that infected cells fix antibody from both the serum of patients with subacute sclerosing panencephalitis and hyper-immunised rabbits, and the patient usually produces some antibody to measles virus. In neither condition is antibody to " $M$ " antigen produced. ${ }^{11}$ It can be argued, therefore, that infection with measles virus can evoke a spectrum of neurological disease, and that it is the state of immune competence of the patient which may be important in determining the clinical manifestations in an individual case.

We are grateful to Dr E Sherwood-Jones for his kind permission to report this case, and to $\operatorname{Dr} M$ Haire for donating potent anti-measles serum.

\section{References}

' Adams JM. Clinical pathology of measles encephalitis and sequelae. Neurology (Minneap) 1968;18:52-86.

${ }^{2}$ Choppin PW. Measles virus and chronic neurological diseases. Ann Neurol 1980;9:17-20.

${ }^{3}$ Lyon G. Examen ultra-structural du cerveau dans trois encephalopathies aigues et chroniques au cours de deficits immunitaires. Arch Fr Pediatr 1972;29:64145.

${ }^{4}$ Murphy JV, Yunis EJ. Encephalopathy following measles infection in children with chronic illness. $J$ Paediat 1976;88:937-42.

${ }^{5}$ Aicardi J, Goutieres F, Arsenio-Nunes ML, Lebon P. Acute measles encephalitis in children with immunosuppression. Paediatrics 1977;59:232-39.

- Pedersen FK, Schiotz PO, Valerius NH, Hertz H. Immunosuppressive measles encephalopathy. Acta Paediatr Scand 1978;67:109-12.

' Wolinsky JS, Swoveland P, Johnson KP, Baringer JR. Subacute measles encephalitis complicating Hodgkins disease in an adult. Ann Neurol 1977;1:452-7.

${ }^{8}$ Lyon G, Ponsor G, Lebon P. Acute measles encephalitis of the delayed type. Ann Neurol 1977;2:322-7.

9 Drysdale HC, Jones LF, Oppenheimer DR, Thomlinson AH. Measles inclusion-body encephalitis in a child with treated acute lymphoblastic leukaemia. J Clin Pathol 1976;29:865-72.

${ }^{10}$ Agamanolis DP, Tan JS, Parker DL. Immunosuppressive measles encephalitis in a patient with a renal transplant. Arch Neurol 1979;36:686-90.

${ }^{11}$ Roos PR, Graves MC, Wollmann RL, Chilcote RR, Nixon J. Immunological and virologic studies of 
measles inclusion body encephalitis in an immunosuppressed host: the relationship to subacute sclerosing encephalitis. Neurology (NY) 1981;31:1263-70.

12 Pullan CR, Noble TC, Scott DJ, Wisniewski K, Gardner PS. Atypical measles infections in leukaemic children on immunosuppressive treatment. $\mathrm{Br}$ Med $J$ 1976;1:1562-5.

${ }^{13}$ Mellor DH, Purcell M. Unusual encephalitic illness in a child with acute leukaemia in remission: possible role of measles virus and toxoplasma gongii. Neuropaediatrie 1976;7:423-30.

${ }^{14}$ Campbell RHA, Marshall WC, Chessels JM. Neurological complications of childhood leukaemia. Arch Dis Child 1977;52:850-8.

is Mandelbaum DE, Hall WW, Paneth N, Wolff RR, Devivo DC. SSPE, measles virus and the matrix protein: report of a case with unusual immunochemical findings. Ann Neurol 1981;10:351-4.

${ }^{16}$ Coulter JBS, Balch N, Best PV. Subacute sclerosing panencephalitis after drug-induced immunosuppression. Arch Dis Child 1979;54:640-2.

${ }^{17}$ Bellman MH, Dick GWA. Surveillance of subacute sclerosing panencephalitis. J $R$ Coll Physicians (Lond) 1978;12:256-61.

${ }^{18}$ Jabbour JT, Garcia JH, Lemmi H, Ragland J, Duenas DA, Sever JL. Subacute sclerosing panencephalitis. A multidisciplinary study of eight cases. JAMA 1969;207:2248-54.

19 Thomas JE, Reagan TJ, Klass DW. Epilepsia partialis continua Arch Neurol 1977;34:266-75.

${ }^{20}$ Zeman W. Subacute sclerosing panencephalitis and paramyxovirus infections. In: Vinken PJ, Bruyn GW, eds. Handbook of Clinical Neurology Vol 34, North Holland, Amsterdam. 1978;343-68.

${ }^{21}$ Gilden DH, Rorke LB, Tanaka R. Acute subacute sclerosing panencephalitis. Arch Neurol 1975;32:644-6.

${ }^{22}$ Silva CA, Paula-Barbosa MM, Pereira S, Cruz C. Two cases of rapidly progressive subacute sclerosing panencephalitis. Arch Neurol 1981;38:109-13.

${ }^{23}$ Smyth D, Tripp JH, Brett EM, Marshall WC, Almeida J, Dayan AD, Coleman JC, Drayton R. Atypical measles encephalitis in leukaemic children in remission. Lancet 1976;2:574. 